\title{
LINHAS E TERRITÓRIOS E BIOLOGIAS MENORES: ELEMENTOS DE UMA CARTOGRAFIA*
}

\author{
Sandro Prado Santos \\ Elenita Pinheiro de Queiroz Silva
}

\section{Caminhos iniciais e a composição de linhas de escrita}

O desejo que impulsionou essa escrita foi produzido pelos bons trâns-itos, movimentos e encontros com corpos, gêneros, sexualidades e Educação em Biologia, a partir de uma investigação de doutorado em que nos dispusemos a cartografar as ressonâncias da aliança: Experiências de pessoas trans - Ensino de Biologia (SANTOS, 2018)1. Nessa rede de alianças, fomos trans-tecendo outras cartografias na Educação em Biologia (SANTOS, 2019a, 2019b, 2000; SANTOS; SILVA, 2019a),

[...] de modo a desfazer um pouco aquilo que se encontrava estratificado em nós, ou aquilo que vemos se repetir em ditos e vistos nas aulas de Biologia, abrindo espaço para que seja possível dizer, sentir, viver e ver de outro modo [...] ou quem sabe esburacar o que se vê e o que se diz de corpos, gêneros e sexualidades. (SANTOS; SILVA, 2019b, p. 102).

Desse modo, a aposta foi numa experimentação provocativa e de múltiplos caminhos que nos fez "[...] olhar e encontrar trilhas diferentes a serem perseguidas, possibilidades de transgressões [...] em quadros que nos parecem fixos demais, em direções que nos parecem por demais lineares". (PARAÍsO, 2005, p. 79).

Foi um caminhar entre Ensino de Biologia - experiências de pessoas

*DOI - 10.29388/978-65-86678-66-6-f.123-138

${ }^{1}$ Tese desenvolvida no Programa de Pós-Graduação em Educação da Faculdade de Educação da Universidade Federal de Uberlândia (2014-2018) na linha de pesquisa "Educação em Ciências e Matemática", vinculada ao Grupo de Pesquisa Gênero, Corpo, Sexualidade e Educação (GPECS) e orientada pela líder do grupo, Elenita Pinheiro de Queiroz Silva. 
trans $^{2}$, um andar pelo meio, intermezzo ${ }^{3}$. De um lado, uma experiência marcada pela criação, pela transgressão, pelos movimentos e deslocamentos. De outro, uma disciplina escolar, um conjunto de práticas discursivas pedagógicas e científicas, livros didáticos, laboratórios, professores/as, alunos/ as, lista de conteúdos, parâmetros curriculares, etc. Um encontro atravessado por movimentos, relações, pelos jogos de poder-saber-verdade, por modos de subjetivações, carregados de densidades e intensidades, por formações rizomáticas, pela composição de dispositivos ${ }^{4}$, por práticas de enfrentamentos, resistências e rupturas, portanto, nos apontando para insurgências de uma cartografia.

Dessa maneira, fomos lançados numa pesquisa que nos embarcou numa viagem "[...] para a qual não existe nenhum mapa prévio", e, na qual fomos forçados "[...] a deixar para trás as pesquisas habituais" sem ter "[...] certeza sobre o lugar onde iria aportar". (TADEU; CORAZZA; ZORDAN, 2004, p. 18). Assim como o "Conto da Ilha Desconhecida" de José Saramago (1998): "[...] Sabes navegar, tens carta de navegação, ao que o homem respondeu, Aprenderei no mar. [...] Mas tu, se bem entendi, vais à procura de uma (ilha desconhecida) onde nunca ninguém tenha desembarcado [...]". (p. 26-27).

\footnotetext{
2 Ressaltamos que utilizamos "experiências de pessoas trans" para não fazer referência direta a uma denominação médica/patológica e por não referenciar um arranjo unívoco entre as muitas possibilidades relacionadas aos deslocamentos de gênero das pessoas trans. Reafirmamos a polifonia das pluralidades de experiências possíveis com/nos corpos, gêneros, sexualidades e desejos. (JESUS, 2012).

${ }^{3}$ Conceito utilizado por Deleuze e Guattari (2011) para se referir "ao rizoma que não começa nem conclui, ele se encontra sempre no meio, entre as coisas, inter-ser [...]". (p. 48).

${ }^{4}$ Michel Foucault (1979) demarca o dispositivo em primeiro lugar enquanto "[...] um conjunto decididamente heterogêneo que engloba discursos, instituições, organizações arquitetônicas, decisões regulamentares, leis, medidas administrativas, enunciados científicos, proposições filosóficas, morais, filantrópicas. Em suma, o dito e o não dito são os elementos do dispositivo. O dispositivo é a rede que se pode estabelecer entre esses elementos. Em segundo lugar, gostaria de demarcar a natureza da relação que pode existir entre esses elementos heterogêneos. Sendo assim, tal discurso pode aparecer como programa de uma instituição ou, ao contrário, como elemento que permite justificar e mascarar uma prática que permanece muda; pode ainda funcionar como reinterpretação desta prática, dando-Ihe acesso a um novo campo de racionalidade. Em suma, entre estes elementos, discursivos ou não, existe um tipo de jogo, ou seja, mudanças de posição, modificações de funções, que também pode ser muito diferente. Em terceiro lugar, entendo dispositivo como um tipo de formação que, em um determinado momento histórico, teve como principal função estratégica dominante". (p. 244).
} 
Pesquisar talvez seja mesmo ir por dentro da chuva, pelo meio de um oceano [...]. Logo, percebemos que não há como indicar caminhos muito seguros ou estáveis. Pesquisar é experimentar, arriscar-se, deixar-se perder. (OLIVEIRA; PARAÍSO, 2012, p. 161).

Não poderíamos começar por um saber-fazer, mas pelos encontros, no fazer. Foi lidar com "[...] nenhum fazer assegurado, nenhum método perfeito". (TADEU; CORAZZA; ZORDAN, 2004, p. 19). Sentia-nos em uma pesquisa sempre em/com fugas que "[...] desterritorializa e descodifica as relações com nós mesmos e com os outros" (p. 22), uma pesquisa "[...] diagramatizada em termos de linhas de fuga". (p.23).

Sendo assim, como chegamos? O que aprendemos com/no fazer cartográfico da investigação? Onde (des)embarcamos na Educação em Biologia? Quais os encontros? Quais as insurgências e irrupções para a Educação em Biologia? Quais pistas, cartografias e percursos outros aos corpos, gêneros e sexualidades com/na Educação em Biologia? Nesse sentido, os propósitos desse texto são: a) apresentar os fios, as linhas, as brechas, (des)aprendizagens, as implicações e a produção de uma perspectiva cartográfica investigativa; e, b) socializar as insurgências e irrupções na Educação em Biologia, resultantes de nossas apostas em uma pesquisa que enveredou pelos caminhos de um modo de investigação perspectivado na cartografia.

Assim, interessa-nos evidenciar nesse momento as nossas apostas em um movimento de pesquisa-cartográfico - com as discussões de corpos, gêneros, sexualidades produzidas pelo encontro "experiências de pessoas trans-ensino de biologia" - e, por efeito, suas ressonâncias e insurgências que favoreceram a produção de possibilidades outras com a educação em biologia.

\section{Encontro entre "experiências de pessoas trans-ensino de biologia": produzindo uma cartografia}

Nesta seção vamos apresentar os fios, as linhas, as brechas, e, sobretudo, as (des)aprendizagens ao longo de uma trajetória de pesquisa implicada em uma perspectiva cartográfica. Um encontro entre "experiências de pessoas trans-ensino de biologia" que produziu cartografias.

Ao iniciar o doutorado, estávamos imersos em uma racionalidade bio-lógica de códigos e regimes que produziam efeitos e fronteiras estáveis 
de coerência entre o corpo, o gênero e a sexualidade, compondo narrativas de um mapa estático da Educação em Biologia. No entanto, ocorreram atravessamentos que nos indicavam percepções de que "[...] mesmo com a 'domesticação' do olhar, existem 'brechas'/'retomadas' para que as coisas tomem algum frescor e novos discursos entrem em cena" (KIRST, 2003, p. 50), levando-nos a desconfiar do mapeamento estático e fixo da Educação em Biologia.

As lembranças das atuações na docência na Educação Básica e no Ensino Superior foram nos apontando pistas de ocorrências de rupturas, tensões e impermanências nos corpos, gêneros e sexualidades no campo da Educação em Biologia. Um campo virtual com traços intensivos que foram potencializando o rompimento de um modelo de pensamento.

Mesmo que nas aulas circulassem regimes de normalização, disciplinarização e controles identitários havia aqueles/as que transbordavam os arranjos produzidos nelas. Nesse movimento, fomos dando conta de que a Educação em Biologia pode ser potente e plural, pode construir sinalizações e possibilidades de pensar outros arranjos nas linguagens dominantes, para assim ampliar os espaços de fissuras e provisoriedade de corpos, gêneros e sexualidades.

Com isso, encontros com perspectivas teórico-metodológicas que privilegiam um resgate do plano da sensibilidade, do plano expressivo da produção de sentidos, das experimentações vividas e potencializações de afetos e brechas foram inevitáveis para a insurgência de uma pesquisa que "[...] se realiza como uma viagem por outros universos de significação que convoca um novo olhar sobre as paisagens [...]". (MAIRESSE, 2003, p. 260). Um fazer que nos colocava, constantemente, num combate com o traçado fixo de meta-narrativas oficiais pela fixidez do fluxo incontrolado dos corpos, gêneros e sexualidades na Educação em Biologia.

Nesse contexto, a cartografia (DELEUZE; GUATTARI, 2011) nos forneceu instrumentos para pensar novas políticas dos corpos, gêneros e sexualidades na contemporaneidade, bem como novas estratégias de resistências no cenário do século XXI (DINIS, 2008), potencializando olhares oblíquos com o campo da biologia.

A escolha da cartografia aconteceu a partir da possibilidade de pensar a produção de uma investigação que evocasse a implicação do pesquisador no campo e a sensibilidade de ouvir histórias, vivências, encontros e experiências de pessoas trans que pudessem expor movimentos de desloca- 
mentos naquilo que está constituído, organizado e naturalizado como corpos, gêneros e sexualidades na Educação em Biologia.

Para Mairesse (2003), a cartografia desencadeia um processo de des-territorialização, estranhamento e potencialização da pesquisa em educação, ao "[...] inaugurar uma nova forma de produzir o conhecimento, um modo que envolve a criação, a arte, a implicação do autor, artista, pesquisa dor, cartógrafo" (p. 259), produzindo deslocamentos nos caminhos, postulados e protocolos fixos, retos, lineares e dados a priori.

A cartografia não parte do nada, [...] parte, sobretudo, de suas paixões, dos seus encontros, do amor pelo que se toca e pelo que se vê. Tomando a contrapelo, desfazendo e recriando o material que lhe é disponível, embarcando em uma linha que os toca, os movimentos do/a cartógrafo/a transbordam as opiniões correntes, seus traços intensivos rompem o pensamento para construir novas composições mundanas para a educação. (OLIVEIRA; PARAísO, 2014, p. 298).

A cartografia opera na produção de mapas, sempre abertos, de relações de forças, mapas de densidade e mapas de intensidade, compostos nos jogos das linhas que não param de misturar matérias de modo a constituir traçados de conexões inesperadas, torções, insurgências, mutações, criatividade e resistências. Sempre em devir. De mapas por vir (DELEUZE, 2013), um modo de desenhar diagramas, traçando e acompanhando movimentos de poder, jogos de verdade, a composição de dispositivos, linhas de força, enfrentamentos. Desse modo, o ato de cartografar se presta ao enfrentamento dos dispositivos, no desemaranhar suas linhas, produzindo rupturas, resistências e des-territorializações de seus modos de operação. (PRADO-FILHO; TETI, 2013).

As contribuições de Michel Foucault, como cartógrafo de nosso tempo e de nosso mundo, é justamente, o deslocamento do olhar "[...] para as bordas constitutivas da racionalidade ocidental" (ALBUQUERQUEJÚNIOR; VEIGA-NETO; SOUZA-FILHO, 2011, p. 9), produzindo:

[...] uma nova geografia de nosso pensamento e de nossas práticas ao ir buscar naquilo que foi considerado minoritário, desviante, criminoso, invisível, ameaçador, as próprias operações fundamentais da constituição do que somos e daquilo que fizemos e fazemos com nós mesmos. (p. 9). 
Nesse contexto, a opção pela cartografia produziu uma conexão com as experiências postas discursivamente às margens e a produção de diagramas de relações de forças e de ressonâncias na Educação em Biologia. Possibilitou-nos encontros que fazem ecos na "[...] vida que pulsa e não para de movimentar-se nos territórios educacionais" (OLIVEIRA; PARAíSO, 2012, p. 163) e, que "[...] não cessam de escapar, de mudar de natureza; que vivem uma organização própria sem a necessidade alguma de um sistema que lhes dê unidade". (p. 161).

Compreendemos, assim, que o princípio de cartografia esboça "[...] um desenho que acompanha e se faz ao mesmo tempo em que os movimentos de transformação da paisagem" com possibilidades de desmanchamento de mundos e formação de outros para o desbloqueio e expressão de afetos contemporâneos. (ROLNIK, 1989, p. 15). Com isso o cartógrafo precisa "[...] dar língua para afetos que pedem passagem, dele se espera [...] que esteja mergulhado nas intensidades de seu tempo e que, atento às linguagens que encontra, devore as que lhe parecem elementos possíveis para a composição das cartografias [...]". (p. 15-16). O cartógrafo "[...] é um verdadeiro antropófago: vive de expropriar, se apropriar, devorar e desovar, transvalorado. Está sempre buscando elementos/alimentos para compor suas cartografias". (ROLNIK, 1989, p. 67, destaques da autora).

A vitalidade e o fazer da cartografia "[...] vem do seu trabalho sobre as linhas [...] expor linhas e possibilidades por elas inauguradas, compondo um mapa de diferentes partes que serve para indicar zonas de indistinção". (OLIVEIRA; PARAÍSO, 2014, p. 289). Com isso, o fazer cartográfico visibiliza "[...] um mundo inundado de movimentos e forças, de traçados e linhas, suas virtudes elementares e seu jogo dinâmico de ressonâncias". (p. 289).

No fazer da jornada cartográfica ficamos atentos e acompanhamos, por um lado, linhas que compunham e atravessavam as experiências das pessoas trans - a linha da experiência do corpo, a linha da experiência do gênero e a linha da experiência da sexualidade. Linhas que apostamos na possibilidade de vazamentos e que poderiam dizer outras coisas com os corpos, gêneros e sexualidades na Educação em Biologia. Por outro lado, as linhas das forças e das formas ou do poder/potência do corpo, do gênero e da sexualidade, linhas do dispositivo da sexualidade e as linhas do dispositi- 
vo da trans-sexualidade 5 que compunham a Educação em Biologia. (SANTOS, 2018).

Com isso agenciamos um encontro, (in)suspeitado e (in)esperado: experiências de pessoas trans-ensino de biologia (SANTOS, 2018), apostando e desejando operar a composição de cartografias distantes de uma organização fechada e de exigências da representação.

Rastros e composições que não vieram antes da pesquisa, pré-existentes, ou que já estavam planejados a priori, foram instaurados na e com a pesquisa, possibilitando cartografias com linhas duras e dadas de um único fio narrativo, compondo corpos, gêneros e sexualidades estratificados, estáveis, previsíveis, bem como cartografias outras com traçados que movimentaram a Educação em Biologia. (SANTOS, 2018).

\title{
Movimentando a educação em biologia: linhas e territórios e biologias menores
}

\begin{abstract}
"Que aconteceu?". Os de ampla visão podem adivinhar o futuro, mas é sempre sob a forma do devir de algo que já aconteceu em uma matéria molecular, partículas inencontráveis. É como em biologia: como as grandes divisões e dicotomias celulares, em seus contornos, são acompanhadas por migrações, invaginações, por deslocamentos, por impulsos morfogenéticos, cujos segmentos não são mais marcados por pontos localizáveis, mas por limiares de intensidade que ocorrem por baixo, mitoses em que tudo se confunde, linhas que se cruzam no interior de grandes células e de seus cortes. É como em uma sociedade: como os segmentos duros e sobrecortantes são cortados por baixo por segmentações de outra natureza. Mas não é nem uma nem a outra, nem biologia nem sociedade, nem semelhança das duas: [...] traço linhas, linhas de escrita, e a vida passa entre as linhas. (DELEUZE; GUATTARI, 2012, p. 81-82).
\end{abstract}

\footnotetext{
${ }^{5}$ Termo utilizado por Berenice Bento (2006) e Fátima Lima Santos (2010) a partir do conceito de dispositivo da sexualidade de Michel Foucault. Arán (2006); Arán, Murta e Lionço (2009); Leite-Júnior (2011); Teixeira (2013); Borba (2016) têm investido na elaboração da emergência desse dispositivo. Nesse sentido, as/os autores/as apontam para as condições de emergência, a invenção, a criação e imposição de saberes que produzem as verdades sobre os corpos transexuais. Segundo Bento (2006) o dispositivo pode se entendido como "[...] o saber específico que define, classifica, normatiza, formula etiologias e nosologias e tem poder de decisão sobre as demandas dos/as transexuais que desejam realizar intervenções em seus corpos [...]". (p. 21).
} 
Durante o caminhar da pesquisa, fomos acompanhando na Educação em Biologia os usos de corpos, gêneros e sexualidades a partir dos encontros com as experiências de pessoas trans que fizeram insurgir deslocamentos, pontos localizáveis, segmentações, mas também limiares de intensidades. Assim, já conseguimos apontar atravessamentos insurgentes de uma composição cartográfica da educação em biologia, esta não é algo:

[...] completamente segmentado, ou inteiramente estratificado, já que toda estratificação segrega a possibilidade de outras relações complicantes, capazes de se combinarem, num plano [...] liso e não segmentado, que permite entre-espaços, disparidades, devires. (TADEU; CORAZZA; ZORDAN, 2004, p. 23).

O que aconteceu com o encontro? Assim, dentre os movimentos que ressoaram e insurgiram, a partir dos trânsitos dos gêneros e sexualidades, na educação em biologia que conseguimos cartografar, destacamos traços e atravessamentos por/entre linhas; a arquitetura de territórios e a inflexão de pequenas redes.

Carto-grafias e alianças com as pessoas trans foram nos dando pistas, nuances e movimentos no mapeamento da educação em biologia que, como em qualquer coisa, há linhas de articulação e segmentaridade, estratos, territorialidades, mas também linhas de fuga, movimentos de desterritorialização e desestratificação. A Educação em Biologia é constituída de/ por multiplicidades de linhas, articuladoras de um jogo de regime, estados de coisas, e, também de movimentos de desterritorialização. Linhas entrecruzadas ora por segmentaridades povoadas de discursos exatos de corpos, gêneros e sexualidades, ora por linhas de fugas de torções e deslocamentos de sentidos.

Asseguramos que a educação em biologia cria territorialidades, arquiteta seus territórios. Com isso, podemos pensá-la como um “[...] território político, ético e estético incontrolável que, se é usada para regular e ordenar, pode também ser território de escapes de todos os tipos com [...] trajetos grávidos de esperança [...]". (PARAísO; CALDEIRA, 2018, p. 14).

Nessa seara, consideramos os gêneros e sexualidades como constitutivos e constituintes da configuração territorial das práticas educativas, curriculares e formativas na Educação em Biologia. Os ditos e vistos desses dispositivos (FOUCAULT, 1979) ecoam e funcionam desde dentro na territorialização e organização do jogo que está na ordem das coisas da educação 
em Biologia, (RANNIERY; LEMOS, 2018), produzindo-a enquanto territórios que oscilam entre planos a partir dos movimentos dos gêneros e sexualidades: de um lado, as superfícies de estratificação, normalizações e (órgão)nização, e, por outro, o plano no qual eles resistem, insistem, conectam, rizomatizam, criam e fluem como campos intensivos. Planos que atuam, operam, funcionam e coexistem ao mesmo tempo nas superfícies territoriais.

Essas operações e movimentos territoriais nos abriram espaços de aproximações ao conceito de "literatura menor" (DELEUZE; GUATTARI, 2015), bem como aos seus desdobramentos em territórios brasileiros, com o campo da educação a partir das produções do filósofo Silvio Gallo ${ }^{6}$. Essa seara fez nos disparar os conceitos de educação em biologia maior e a educação em biologia menor como dispositivos para pensar as discussões de gênero e sexualidade nos territórios da educação em biologia. (SANTOS; MARTINS, 2020).

No âmbito de uma educação em biologia maior temos a instituição de um ensino sobre os gêneros e sexualidades a partir de campos neutros, não políticos, desapartados dos processos de socialização e sedimentados na universidade do organismo bio-lógico, produzindo grandes mapas e projetos com narrativas estáticas e com fronteiras fixas de uma organização estrutural orgânica, submetidos à primazia das explicações biológicas, proscrevendo-os do campo das experienciações. No entanto, também, encontramos pistas de que as discussões de gênero e sexualidade, na disciplina escolar Biologia, tem se assentado em outros lugares (abrindo espaços para uma biologia menor de afirmação dos corpos, gêneros e sexualidades), distantes daqueles em que estão acostumadas a serem sedimentadas, potencializando a produção de práticas educativas comprometidas com os modos singulares de gêneros e sexualidades.

Nesse sentido, encontramos trincheiras (espaços) nos territórios da educação em biologia, com possibilidades de re-invenção de modos singula-

\footnotetext{
${ }^{6}$ GALLO, Sílvio. Em torno de uma educação menor. Educação \& Realidade, Porto Alegre, v.27, n. 2, p.169-178, jul./dez. 2002. GALLO, Sílvio. Educação menor: produção de heteropotias no espaço escolar. In: RIBEIRO, Paula Regina Costa. et al. (Orgs.). Corpo, gênero, sexualidade: discutindo práticas educativas. Rio Grande: Editora FURG, p. 93-102, 2007. GALLO, Sílvio. Em torno de uma educação menor: variáveis e variações. In: $36^{\circ}$ REUNIÃO NACIONAL DA ANPED. Anais... 29 de setembro a 02 de outubro de 2013, Goiânia/GO, p. 1-12. GALLO, Sílvio. mínimo múltiplo comum. In: RIBETTO, Analice. (Org.). políticas, poéticas e práticas pedagógicas (com minúsculas). $1^{a}$ edição. Rio de Janeiro: Lamparina, FAPERJ, 2014, p. 20-33. GALLO, Sílvio. Deleuze \& a Educação. 3.ed. Belo Horizonte: Autêntica Editora, 2016.
} 
res de gêneros e sexualidades, produzindo um funcionamento menor da biologia que esburaca e mina os espaços de uma educação maior que impõe um caminho único aos gêneros e sexualidades, oferecendo resistências.

Se uma educação em biologia maior, no contexto dos diálogos com os gêneros e as sexualidades, está implicada na produção de elementos de homogeneização, da binarização, da neutralidade, da representação, invariabilidade, estabilização, vontade de saber-poder, de uma totalidade orgânica, constâncias e universalizações, a biologia menor nos apresenta como uma máquina de resistência a tais usos.

Uma educação em biologia menor desterritorializa e arranca dos territórios o lugar fixador dos gêneros e sexualidades, abrindo brechas e fissuras no que se vê e no que se diz aos/dos gêneros e sexualidade nos processos educativos estabelecidos, aflorando, produzindo conexões e relações incessantes com outras cartografias e territorialidades para que se possa dizer, pensar, viver, sentir, experimentar, inventar corpos, gêneros e sexualidades outros, singulares. Há uma abertura que remete a ramificações, buscas, fugas, novos encontros, mergulhando os territórios numa heterogeneidade e multiplicidade de vozes que não interditam os gêneros e as sexualidades às genitálias, às configurações cromossômicas, às linguagens bioquímicas e às estruturações neuroanatômicas, fazendo percorrer não-linearidades, zonas de variações, conjunções com o campo biológico, social, histórico, filosófico, artístico e... visibilizando outras riquezas (multiplicidades) que estavam ali minorizadas e invisibilazadas.

\section{(In)conclusões}

O investimento em uma investigação cartográfica - da aliança entre experiência de pessoas trans com a educação em biologia - assegurou as insurgências de linhas, territórios, biologias menores e outros funcionamentos que pôs a trepidar usos maiores de territórios normativos e prescritivos, fazendo emergir pequenas redes (minoritárias) de biologias outras que coexistem, e, no entanto, pouco tem sido pensada, movimentada e visibilizada nos espaços-tempos escolares.

Biologias que nos provocaram exercícios de cartografias outras nos territórios, fazendo ressoar carto-grafias menores e minúsculas: invenção de mundos possíveis. linhas de fuga. vitalismo. conexões. lugares outros. heterogeneidades. multiplicidades. alianças. intensidades. contrasexualida- 
de. espaços híbridos-repletos de reentrâncias. entrelaçamentos. narrativas. irrupção. dobras. radículas difusas. contingências moventes. paisagens de vivências. experimentações rizomáticas mudanças. microfissuras. desterritorializações. política. vontade de potência. criação. tecnologias de resistência. variação. $n$ sexualidades e gêneros. devires. sub-versões. fluxos. errantes. resistência. linhas. ruídos. tecnologias sócio-políticas. afectos. polifonia. espaços movediços? ${ }^{7}$.

Nesse sentido, apostamos em pensar uma educação em biologia que busque romper com uma cartografia fixa e determinista, indo ao encontro de suas constituições de fluxos, de redes, de vazamentos, de composições e deslizamentos, de minoridades e de campos de disputas de sentidos.

Assim, no desejo de não encerrar essa conversa com a educação em biologia, deixaremos aqui uma provocação, do poeta Bernardo Enoch Mota, para continuarmos criando cartografias outras e re-existências aos usos de uma Biologia Maior:

Eu não

Eu não odeio meu corpo.

Eu não nasci no corpo errado. Não me venha falar que ele é inadequado.

Se eu mudo é para melhorar o que sinto que possa ser melhorado. Se eu mudo é porque mudança faz parte da vida e eu não quero me sentir parado.

Cada forma. Cada traço. São todos pedaços de quem eu sou.

Comecei só como um rabisco. Agora estou transcendendo o padrão fabricado.

E ninguém tem nada com isso.

E não tem nada de errado.

Eu sou eterno rascunho da vida.

\footnotetext{
${ }^{7}$ Esses conceitos e afetos compõem um exercício de encontros e insurgências de modos de pensar aberturas de leituras e variações com a educação em biologia a partir de pesquisas em gênero-sexualidade-educação em biologia, pelas quais passamos e as quais passam por nós, assim tentamos tecer minúsculas alianças que possam fazer insurgir vibrações nas complexas configurações territoriais. Com isso produzimos um "Manifesto: linhas e maquinações e minorações e biologias e...”. (SANTOS; MARTINS, 2020). In: Revista Coletiva - Coluna: Educação e diferenças e... n.14. novembro/2020. (no prelo).
} 
Nunca vou ser terminado. Apaga. Refaz. Tira. Acrescenta.

Só não deixa igual, porque aí ninguém aguenta.

Eu não odeio meu corpo. Eu não nasci no corpo errado.

Sou eterno rascunho da vida, estou aqui

para ser melhorado.

$\mathrm{Na}$ eterna busca do buscar por toda eternidade.

Rabisco Rascunho Desenho Obra prima Transbordando Transcenden-

do Transgredindo

Apenas sendo mais eu

Mais meu a cada dia.

Bernardo Enoch Mota ${ }^{8}$

Continuaremos defendendo e cartografando uma educação em biologia menor para que ela ganhe força, continue re-existindo e se reinventando para ganhar outros rabiscos, desenhos, desd(obra)mentos e trans-bordamentos.

\section{Inter-ferências:}

ALBUQUERQUE-JÚNIOR, Durval Muniz de.; VEIGA-NETO, Alfredo.; SOUZAFILHO, Alípio de. Uma cartografia das margens. In: ALBUQUERQUE-JÚNIOR, Durval Muniz de.; VEIGA-NETO, Alfredo.; SOUZA-FILHO, Alípio de. (Orgs.). Cartografias de Foucault. 2.edição. Belo Horizonte: Autêntica, 2011, p. 912.

ÁRAN, Márcia. A transexualidade e a gramática normativa do sistema sexogênero. Ágora, Rio de Janeiro, v. IX, n.1, jan./jun. 2006, p. 49-63.

ÁRAN, Márcia.; MURTA, Daniela.; LIONÇO, Tatiana. Transexualidade e saúde pública no Brasil. Ciência \& Saúde Coletivo, v.14, n.4, 2009, p. 1141-1149.

BENTO, Berenice. A reinvenção do corpo: sexualidade e gênero na experiência transexual. Coleção Sexualidade, Gênero e sociedade. Rio de Janeiro: Garamond, 2006.

${ }^{8}$ In: ANTOLOGIA Trans. 30 poetas trans, travestis e não-binários. São Paulo: Invisíveis Produções, 2017. 
BORBA, Rodrigo. O (Des)Aprendizado de si: transexualidades, interação e cuidado em saúde. Rio de Janeiro: Editora FIOCRUZ, 2016.

FOUCAULT, Michel. Microfísica do Poder. Tradução de Roberto Machado. Rio de Janeiro: Edições Graal, 1979.

DELEUZE, Gilles. Foucault: Gilles Deleuze. Tradução Claudia Sant'Anna Martins. São Paulo: Brasiliense, 2013.

DELEUZE, Gilles.; GUATTARI, Félix. Mil Platôs, v.1. Tradução de Ana Lúcia de Oliveira, Aurélio Guerra Neto e Célia Pinto Costa. São Paulo: Editora 34. 2011.

DELEUZE, Gilles.; GUATTARI, Félix. Mil Platôs, v.3. Tradução de Aurélio Guerra Neto, Ana Lúcia de Oliveira, Lúcia Cláudia Leão e Suely Rolnik. São Paulo: Editora 34. 2012.

DELEUZE, Gilles.; GUATTARI, Félix. Kafka: por uma literatura menor. Tradução Cíntia Vieira da Silva. 1.ed. Belo Horizonte: Autêntica Editora, 2015.

DINIS, Nilson Fernandes. A esquizoanálise: um olhar oblíquo sobre corpos, gêneros e sexualidades. Sociedade e Cultura, v.11, n.2, jul./dez. 2008, p. 355-361.

JESUS, Jaqueline Gomes de. Orientações sobre a população transgênero: conceitos e termos. Brasília: Autor, 2012.

KIRST, Patrícia Gomes. Redes do olhar. In: FONSECA, Tania Mara Galli; KIRST, Patrícia Gomes. (Orgs.). Cartografias e devires: a construção do presente. Porto Alegre: Editora da UFRGS, 2003, p. 43-52.

LEITE-JÚNIOR, Jorge. Nossos corpos também mudam: a invenção das categorias "travesti" e "transexual" no discurso científico. São Paulo: Annablume, FAPESP, 2011. 
MAIRESSE, Denise. Cartografia: do método à arte de fazer pesquisa. In: FONSECA, Tania Mara Galli.; KIRST, Patrícia Gomes. (Orgs.). Cartografias e devires: a construção do presente. Porto Alegre: Editora da UFRGS, 2003, p. 259-272.

OLIVEIRA, Thiago Ranniery Moreira.; PARAÍsO, Marlucy Alves. Mapas, dança, desenhos: a cartografia como método de pesquisa em Educação. Proposições, v.23, n.3, set./dez. 2012, p. 159-178.

OLIVEIRA, Thiago Ranniery Moreira.; PARAÍSO, Marlucy Alves. Mapas, dança, desenhos: a cartografia como método de pesquisa em Educação. In: MEYER, Dagmar Estermann.; PARAísO, Marlucy Alves (Orgs.). Metodologias de pesquisas Pós-Crítica em Educação. 2a edição. Belo Horizonte: Mazza Edições, 2014, p. 281-306.

PARAÍSO, Marlucy Alves. Currículo-mapa: linhas e traçados das pesquisas pós-críticas sobre currículo no Brasil. Educação \& Realidade, v.30, n.1, jan./ jun. 2005, p. 67-82.

PARAÍSO, Marlucy Alves.; CALDEIRA, M. C. S. Apresentação. In: PARAÍsO, M. A.; CALDEIRA, M. C. S. (Orgs.). Pesquisas sobre currículos, gêneros e sexualidades. Belo Horizonte: Mazza Edições, 2018, p. 13-21.

PRADO-FILHO, Kleber.; TETI, Marcela Montalvão. A cartografia como método para as Ciências Humanas e Sociais. Barbarói, Santa Cruz do Sul, n.38, jan./jun. 2013, p. 45-59.

RANNIERY, T.; LEMOS, P. C. de. Gênero pode ser uma categoria útil para o ensino de Biologia? In: VILELA, M. L. et al. (Orgs.). Aqui também tem currículo! Saberes em diálogo no ensino de biologia. Curitiba: Editora Prismas. ISBN: 978-85- 537-0044-8. 2018, p. 65-86.

ROLNIK, Suely. Cartografia sentimental: transformações contemporâneas do desejo. São Paulo: Estação Liberdade, 1989. 
SANTOS, Maria de Fátima Lima. A construção do dispositivo da transexualidade: saberes, tessituras e singularidades das experiências trans. 2010. 183f. Tese (Doutorado em Saúde Coletiva) - Programa de Pós-Graduação em Saúde Coletiva, Universidade do Estado do Rio de Janeiro, Rio de Janeiro, 2010.

SANTOS, Sandro Prado. Experiências de pessoas trans - ensino de Biologia. 2018. 289 f. Tese (Doutorado em Educação). Programa de Pós-Graduação em Educação, Universidade Federal de Uberlândia, Uberlândia, 2018.

SANTOS, Sandro Prado. Encontro-grafias: rabiscos na invenção do caminhouno aos corpos nos territórios da educação em biologia. UIVO: Revista do grupo de pesquisa Uivo: Matilha de estudos em arte, criação e vida. v.1, n.1. 2019a. p. 110-126.

SANTOS, Sandro Prado. Cartografias das experiências de pessoas trans com os territórios da Educação em Biologia. In: 39ª REUNIÃO NACIONAL DA ASSOCIAÇÃO NACIONAL DE PÓS-GRADUAÇÃO E PESQUISA EM EDUCAÇÃO (ANPED). Anais... Niterói/RJ: Universidade Federal Fluminense, out. 2019b, p. 1-7.

SANTOS, Sandro Prado. Experiências de pessoas trans: um problema de saúde para o Ensino de Biologia? In.: CHAVES, S. N. et al. Vidas que ensinam o ensino da vida. 1.ed. São Paulo: Editora Livraria da Física, 2020, p. 243-258.

SANTOS, Sandro Prado.; SILVA. Elenita Pinheiro de Queiroz. Experiências de pessoas trans: corpo, gênero, sexualidade e o ensino de biologia. In.: TEIXEIRA, P. P.; OLIVEIRA, R. D. V. L. de.; QUEIROZ, G. R. P. C. (Orgs.). Conteúdos cordiais: biologia humanizada para uma escola sem mordaça. 1.ed. São Paulo: Editora Livraria da Física, 2019a, p. 17-32.

SANTOS, Sandro Prado.; SILVA. Elenita Pinheiro de Queiroz. Trans-tecendo os territórios da Educação em Biologia: tessituras com os corpos, gêneros e sexualidades. In: RIZZA, J. L. et al. (Orgs.). Tecituras sobre corpos, gêneros e sexualidades no espaço escolar. Rio Grande: Ed. da FURG, 2019b, p. 99-110. 
SANTOS, Sandro Prado.; MARTINS, M. M. Entre encontros e ensino de biologia e gêneros e sexualidades: sopros e insurgências de uma biologia menor. Revista de Ensino de Biologia da SBEnBio, [S. I.], v. 13, n. 1, p. 141-152, 2020. DOI: 10.46667/renbio.v13i1.314. Disponível em: http://sbenbio.journals.com.br/index.php/sbenbio/article/view/314.

SARAMAGO, José. $\mathbf{O}$ conto da ilha desconhecida. São Paulo: Companhia das Letras, 1998.

TADEU, Tomaz.; CORAZZA, Sandra.; ZORDAN, Paola. Linhas de Escrita. Belo Horizonte: Autêntica, 2004.

TEIXEIRA, Flávia do Bonsucesso. Dispositivos de dor: saberes-poderes que (con)formam as transexualidades. São Paulo: Annablume; FAPESP, 2013. 